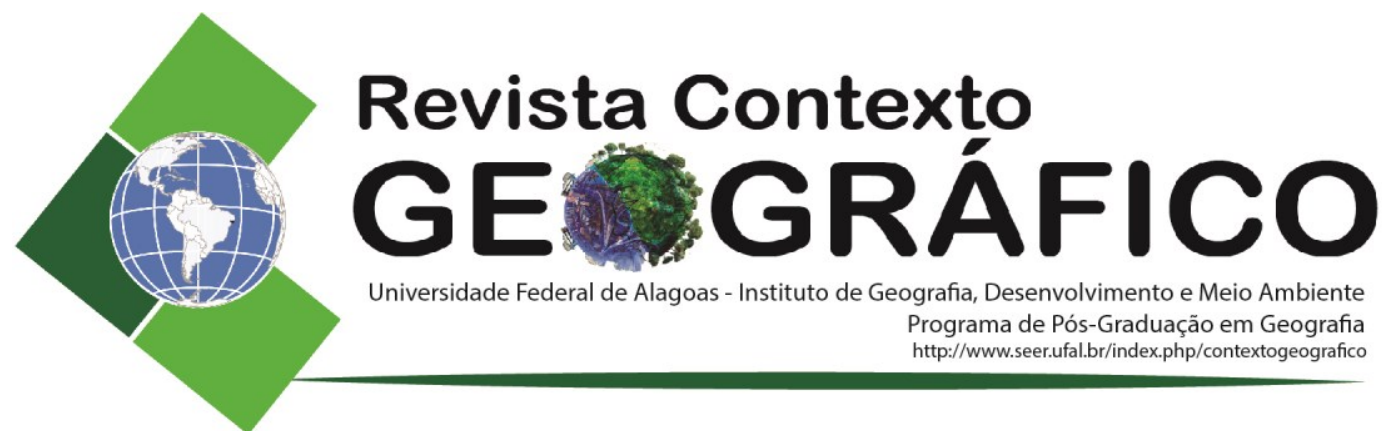

\title{
O ESTUDO DO LUGAR A PARTIR DA PRODUÇÃO DE DESENHOS NA GEOGRAFIA ESCOLAR
}

\author{
Thiago Calheiros Dantas \\ Universidade Federal de Alagoas, Instituto de Geografia, Desenvolvimento e Meio Ambiente, \\ Maceió, AL, Brasil \\ thiagocalheirosdantas@gmail.com \\ Maria Francineila Pinheiro dos Santos \\ Universidade Federal de Alagoas, Instituto de Geografia, Desenvolvimento e Meio Ambiente, \\ Maceió, AL, Brasil \\ francineilap@gmail.com
}

\begin{abstract}
RESUMO - Discute-se neste artigo as percepções dos professores e licenciandos em Geografia acerca do conceito de lugar e de como este vem sendo trabalhado na Geografia Escolar. A opção por esta temática surgiu a partir da realização da oficina Múltiplas Linguagens no Ensino de Geografia, na qual foram analisados diferentes recursos didáticos para auxiliar a prática docente, dentre eles o desenho, visto enquanto instrumento metodológico importante na construção do conceito de lugar. O lugar neste trabalho é entendido como uma dimensão do espaço vivido que é dialeticamente construído pela sociedade, onde percebemos a dinâmica do lugar-mundo. A análise dos desenhos produzidos permite concluir que os docentes representam relações presentes no seu cotidiano, notadamente através da ação verticalizada de alguma empresa ao ocupar um espaço e ocasionar de certo modo a retirada dos mais pobres, apontando criticas relacionadas a desigualdade social, e denotando o sentimento de pertencimento ao lugar em que vivem.
\end{abstract}

Palavras-chave: Múltiplas Linguagens; Ensino de Geografia; Escola.

\section{THE STUDY OF THE PLACE FROM THE PRODUCTION OF DRAWINGS IN SCHOOL GEOGRAPHY}

\begin{abstract}
This article discusses the perceptions of teachers and graduates in Geography about the concept of place and how it has been worked in School Geography. The option for this theme emerged from the realization of the workshop Multiple Languages in Geography Teaching, in which different didactic resources were analyzed to assist the teaching practice, among them drawing, seen as an important methodological tool in the construction of the concept of place. The place in this work is understood as a dimension of the lived space that is dialectically constructed by society, where we perceive the dynamics of the place-world. The analysis of the drawings produced allows us to conclude that teachers represent present relations in their daily lives, especially through the vertical action of a company by occupying a space and in some way causing the withdrawal of the poorest, pointing out criticisms related to social inequality and denoting the sense of belonging to the place in which they live.
\end{abstract}

Keywords: Multiple Languages; Geography School.

\section{INTRODUÇÃO}

O objetivo deste artigo é analisar as concepções dos licenciandos e professores de Geografia acerca do conceito de lugar e o modo como este vem sendo trabalhado na Geografia Escolar. A importância deste trabalho justifica-se por revelar uma leitura crítica dos espaços vividos pelos participantes da pesquisa e desta forma, auxiliar a prática do docente de Geografia.

A Geografia Escolar compreende uma “[...] ampliação científica necessária ao desenvolvimento do ensino básico de Geografia, a fim de instrumentalizá-lo no 
enfrentamento dos desafios de aprendizagem do mundo contemporâneo" (OLIVEIRA, 2009, p.298) permitindo a utilização de metodologias que viabilizam o entendimento dos conceitos centrais da Geografia, dentre eles: o Lugar.

Neste artigo, o conceito de lugar será compreendido como uma dimensão do espaço vivido, no qual o mesmo compreende o "[...] conjunto dos lugares de vida de um indivíduo. A casa, o lugar de trabalho, o itinerário de um a outro local, formando os componentes principais do espaço vivido" (PONTUSCHKA, 2008, 293), o qual é dialeticamente construído pela sociedade, onde percebemos a dinâmica do lugar-mundo.

O presente artigo está sendo desenvolvido a partir de consultas bibliográficas, livros, e revistas cientificas, bem como da análise dos desenhos produzidos pelos licenciandos e professores de Geografia envolvidos na oficina Múltiplas Linguagens no Ensino de Geografia realizada na Universidade Federal de Alagoas - UFAL em junho de 2011. Esta experiência deu origem a reflexões e discussões acadêmicas sobre o conceito de lugar no ensino de Geografia e do desenho enquanto instrumento metodológico na prática docente.

Nesta perspectiva, aponta-se o conceito de lugar sob duas perspectivas, a saber: a Geografia Marxista (histórico-dialética) e a Geografia Humanística, levando em consideração as concepções de lugar no ensino de Geografia, revelando tanto a dialética do sistema de capital, quanto às relações cotidianas dos indivíduos na escala local.

Para se discutir as concepções de lugar(res) dos professores de Geografia e como este vem trabalhando o mesmo em suas aulas, valemo-nos dos desenhos produzidos por dois licenciandos em Geografia (formação inicial) e dois professores de Geografia (formação continuada) na oficina Múltiplas Linguagens no Ensino de Geografia.

Ao todo, foram 30 participantes na oficina, onde tiveram contato com os diferentes recursos didáticos como: a charge, o vídeo, a música e o desenho. No que se refere ao desenho verificouse o mesmo como um importante instrumento de investigação para o ensino de Geografia, o qual possibilita uma leitura das diferentes relações do ser humano com seus espaços de vivência, sendo através do desenho que os discentes e docentes representaram as diferentes dimensões de seu cotidiano, na qual a maioria das vezes não é utilizada durante as aulas de Geografia. O desenho apresenta-se como um grande revelador destas experiências, o qual segundo Pontuschka (2008, p. 293) o mesmo revela "[...] que o não dito se expressa nas formas, nas cores, na organização e na distribuição espacial", acredita-se que o desenho também possibilite ao professor informações sobre as individualidades dos alunos em sala de aula, podendo elas ser ou não reveladas nos esquemas gráficos.

\section{METODOLOGIA}

A metodologia utilizada foi baseada na pesquisa qualitativa, a qual segundo Lüdke \& André (1986, p. 13) é "aquela que envolve a obtenção de dados descritivos, obtidos no contado direto do pesquisador com a situação estudada, enfatiza mais o processo do que o produto e se preocupa em retratar a perspectiva dos participantes", aproximando-se de um determinado foco.

Desse modo, este artigo é de natureza qualitativa, inserido em uma perspectiva que explora as diferentes concepções de lugar, reveladas a partir da utilização de desenhos e das justificativas (textos) produzidos pelos sujeitos que participaram da supracitada oficina. Compreende-se, que os elementos gráficos e textuais podem ser interpretados, uma vez que estes se repetem em seus aspectos particulares e gerais, levando em consideração o conceito de lugar.

A escolha por uma metodologia de caráter qualitativo deu-se por acreditar que esta esteja mais apropriada a realização deste estudo, tendo em vista que a estratégia de pesquisa foi desenvolvida por meio dos desenhos dos licenciandos e dos professores, buscando através 
destes desvendar as suas concepções acerca do conceito de lugar, além de demonstrar-lhe um excelente instrumento a ser utilizado na prática docente.

Optou-se, pela coleta de dados, partindo da seguinte solicitação: "desenhem o que vocês sabem ou entendem sobre o conceito de lugar e, em seguida, no verso da folha, justifique o porquê de ter feito este desenho". Obtendo-se 30 desenhos e 30 justificativas, as quais foram selecionadas quatro consideradas representativas, quanto às perspectivas: histórico-dialética e humanística da Ciência Geográfica ressaltando aspectos como: identidade, os espaços opacos e luminosos, as verticalidades e horizontalidades, as quais se referem ao conceito de lugar. Ademais, foi construído um "mural de opiniões", onde cada participante pôde expressar sua interpretação sobre o conceito de lugar, partindo da seguinte solicitação: "escrevam o que vocês sabem ou entendem sobre o conceito de lugar", assim foram obtidos 30 testemunhos que destacam as já citadas perspectivas.

Tendo em vista a preservação da identidade dos sujeitos participantes desta pesquisa, não serão expressos neste artigo os nomes dos licenciandos e professores que participaram da oficina, por motivos éticos, logo, serão identificados pelas letras: A; B; C e D, exemplo (Participante A).

Nesta perspectiva, este artigo consubstancia-se por meio de leituras bibliográficas, representação gráfica, justificativas dos desenhos e produção das diferentes concepções de lugar construídas pelos participantes da oficina, para que assim, pudéssemos fazer as primeiras considerações sobre a análise do corpus.

\section{RESULTADOS E DISCUSSÃO}

\section{O Estudo do Lugar na Geografia Escolar}

Santos (2006, p. 218) salienta que o lugar "é uma referência pragmática ao mundo, do qual vêm solicitações e ordens precisas de ações condicionadas, mas é também o teatro insubstituível das paixões humanas", acredita-se que o conceito de lugar nas aulas de Geografia permita ao professor motivar seus alunos ao pensamento crítico sobre o espaço habitado para que possam perceber as diferentes configurações socioespaciais, estimulando os alunos a entender que colaboram na dinâmica do espaço.

A discussão e a compreensão de conceito pressupõem interações pedagógicas desenvolvidas entre o docente e os discentes, nas quais os sujeitos devem exercitar mecanismos que auxiliem a construção cognitiva de conceitos por meio de processos, como: representação, abstração e interpretação. Nesta direção, propor procedimentos que envolvam delimitação, comparação, explicação, possibilita agregar questões mais complexas que se manifestam no espaço geográfico local ao global ou vice-versa.

Sobre a representação de lugares próximos a uma criança Callai $(2005$, p. 244), aponta que a mesma " [...] estará fazendo escolhas e tornando mais rigorosa a sua observação. Poderá desse modo, dar-se conta de aspectos que não eram percebidos, poderá levantar novas hipóteses para explicar o que existe, poderá fazer críticas e até encontrar soluções". Ou seja, a criança ou o adulto poderá realizar escolhas, críticas ao seu espaço de vivência ou lugar distante, dar sugestões e tornar mais rigorosa sua observação do lugar.

Nesta perspectiva, o desenho do lugar possibilita os alunos a representar sua casa, rua, bairro, promovendo que eles venham entender as diferentes configurações dos espaços representados, e assim aguçando sua habilidade de observação e a memória. Por conseguinte, este processo pode também direcionar os alunos a apreender que os lugares obedecem a uma dinâmica ligada ao território e que existem diferentes atores que o dinamiza.

Sendo assim, o conceito de lugar é demonstrado neste artigo seguindo duas perspectivas teóricas para auxiliar o dia-a-dia do professor de Geografia, a saber: a histórica dialética que 
está ligada a preceitos marxistas e a perspectiva humanística, ressaltando as relações afetivas dos sujeitos com os lugares e com o outro.

A perspectiva marxista considera que o lugar é percebido dentro de um processo de formação histórica e cultural que é único, sendo assim uma expressão da globalidade, para Carlos (1996, p.140) "[...] o mundial que existe no local, redefine seu conteúdo sem todavia anularem-se as particularidades", isto é, o lugar é a base de uma construção social, onde as pessoas desenvolvem uma identidade, entendido como a sede de constantes (re)organizações por forças endógenas e exógenas, o lugar nesta perspectiva é produto de uma razão global-local e local-global.

Já a perspectiva humanística retratada por Tuan e Relph (apud LEITE, 1997, p.10) ressalta que o lugar é o produto das relações afetivas dos sujeitos com seu ambiente, estima-se como "[...] um centro de significados construído pela experiência", ou seja, um conjunto de laços sentimentais que os sujeitos possuem em seus espaços de vivência.

Para Tuan (1980, p.107) "Mais permanentes e mais difíceis de expressar, são os sentimentos que temos para com um lugar, por ser o lar, lócus seus de reminiscências e o meio de se ganhar a vida", ou seja, o lugar na perspectiva humanística é o lócus das experiências, onde acontecem as relações sociais. Sendo assim, Relph $(1999$, p.76) ressalta que o lugar compreende " [...] um centro de significados e, por extensão, um forte elemento de comunicação, de linguagem, mas que nunca seja reduzido a um símbolo despido de sua essência espacial, sem a qual se torna outra coisa, para a qual a palavra "lugar" é, no mínimo, inadequada". Portanto, o lugar não é um ponto no espaço, é um centro de significados, o qual não pode ser sintetizado apenas como um símbolo ou localização, porque as pessoas e os diferentes agentes que o compõe the conferem ânimo, movimento, e dotam o mesmo de significado.

Acredita-se que a partir do desenho de lugar como recurso didático, os alunos podem representar um momento do seu cotidiano possibilitando aos mesmos tanto entender a dinâmica socioespacial, quanto as relações de pertencimento com o lugar e com o outro.

O desenho nas aulas de Geografia deve ser utilizado como recurso didático, auxiliando o professor e tornando possível o desenvolvimento cognitivo do aluno acerca da realidade representada.

\footnotetext{
Os desenhos espontâneos em diferentes faixas etárias e níveis socioeconômicoculturais possibilita identificar o desenvolvimento gráfico-espacial dos alunos como uma representação do mundo próximo e conhecer não só suas informações sobre os lugares próximos a ele, mas também seu imaginário sociocultural (PONTUSCHKA, 2007, p.293).
}

Apoiando-se nas constatações da referida autora, pode-se afirmar a relevância do desenho nas discussões sobre o conceito de lugar no ensino de Geografia, contribuindo para a leitura de mundo dos alunos, permitindo que estes entendam o espaço geográfico e os diferentes fenomênos socioespaciais interconectados ao cotidiano deles.

No que se refere a realização da oficina Múltiplas Linguagens no Ensino de Geografia, a mesma foi baseada na idéia de autores como Callai (1998); Carlos (1996, 2007) e Cavalcanti $(1998,2008,2009)$, os quais consideram os professores e alunos como sujeitos ativos do processo de ensino-aprendizagem.

A análise dos desenhos dos participantes da oficina apontaram duas perspectivas geográficas relacionadas ao conceito de lugar: a humanística e ao materialismo histórico dialético. E revelaram ainda uma tendência para as relações ligadas ao cotidiano de cada sujeito, os quais foram evidenciados nos desenhos, nas justificativas e nas concepções sobre o lugar expostos no mural de opiniões. 
Nesta perspectiva, irei evidenciar alguns resultados do estudo realizado. Inicialmente, a figura 1 ressalta o desenho sobre as questões ligadas à localização da casa do discente e a sua conexão com o mundo.

Figura 1. (PARTICIPANTE A): Desenho do discente do curso de Geografia - Maceió/AL.

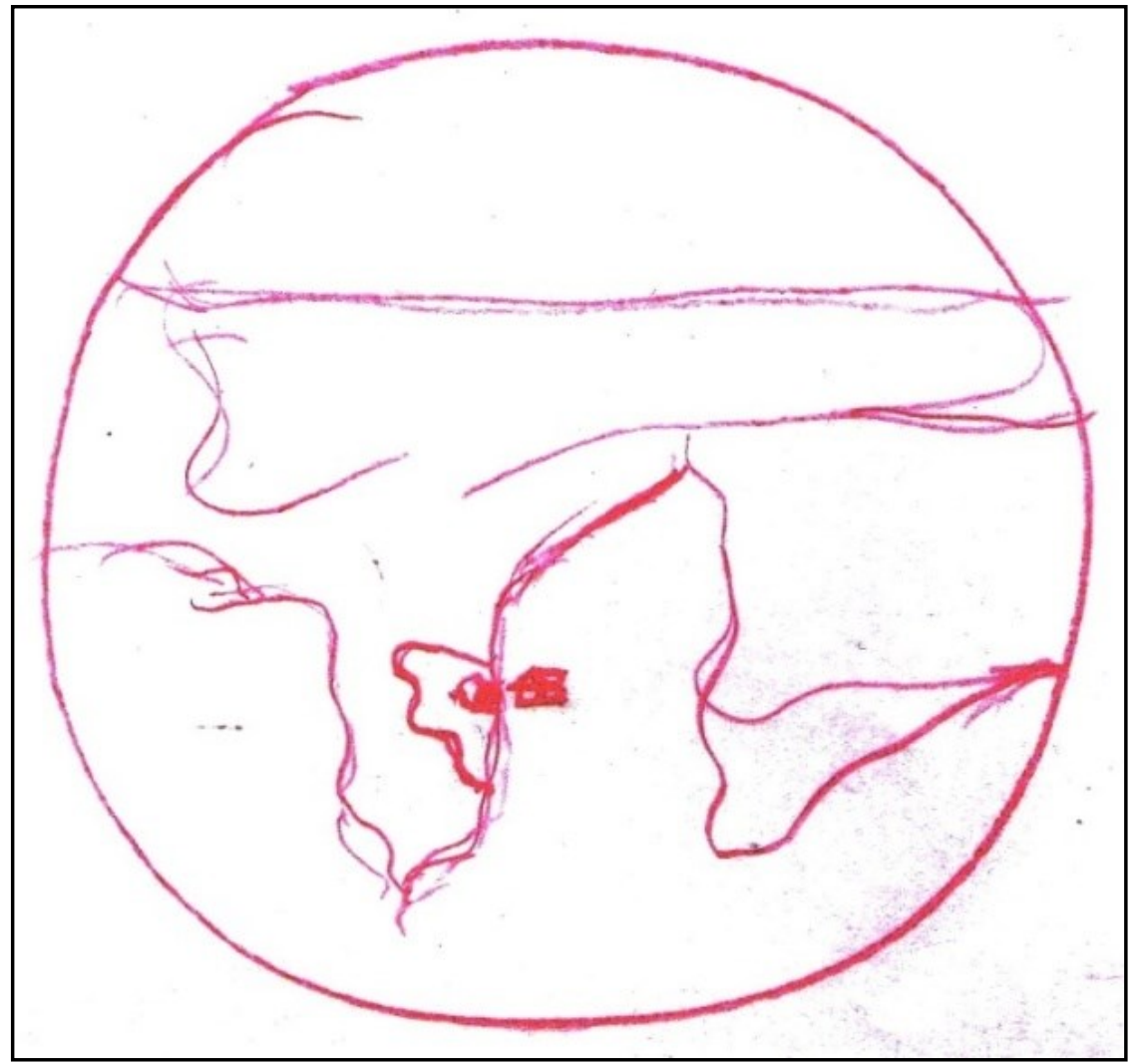

Fonte: DANTAS, (2011)

De acordo com a figura 1, o discente situou a casa onde mora no continente americano, dando a entender que a direita da casa esteja o continente africano. Logo, o espaço que divide ambos os continentes é oceano Atlântico. A representação da casa é destacada dentro de um subespaço, o Estado de Alagoas, situando sua morada em contraponto ao mundo. Entende-se que a noção de escala geográfica aparece de forma sutil, porque a casa está contida em sub-regiões, considerando o mundo, o continente e o Estado.

A justificativa do discente para o desenho foi: "a minha casa inscrita no estado de Alagoas, que está no país Brasil localizando dentro do planeta Terra. Dando a idéia do Local do Global" (Participante A). Diante desta concepção, pode-se inferir que o lugar está sendo representado "[...] como ponto de articulação entre a mundialidade em constituição e o local enquanto especificidade concreta" Carlos (apud CAVALCANTE, 2009, p.141), isto é, só poderemos entender o lugar quando levamos em consideração processos mais amplos, porque apenas a relação local-local não consegue explicar o mundo do presente.

Em relação à figura 2, o discente expõe a imposição das grandes empresas (re)organizando a infra-estrutura urbana, modificando a paisagem e dinamizando as relações econômicas. 
Figura 2. (PARTICIPANTE B): Desenho do discente do curso Geografia - Maceió/AL.

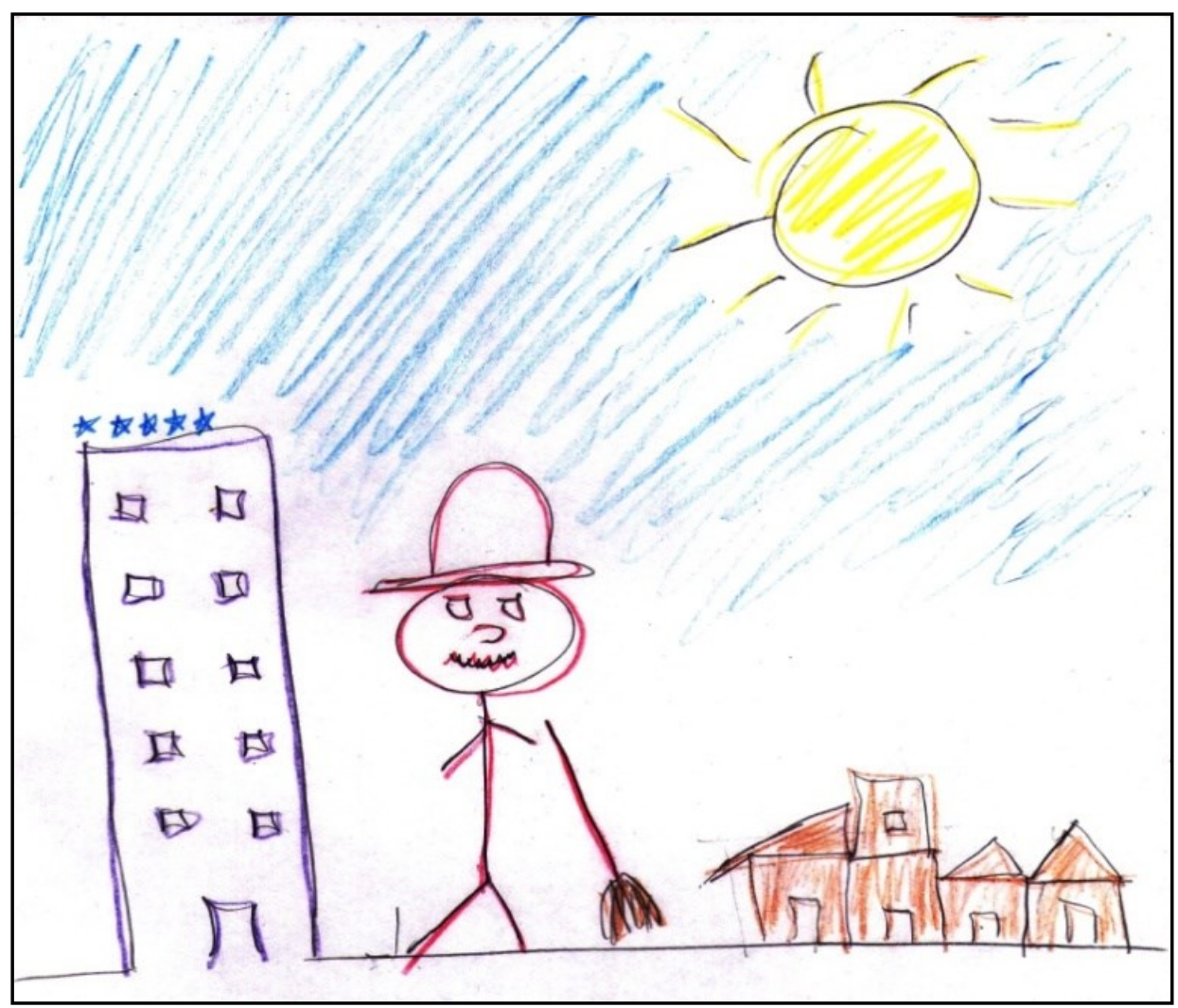

Fonte: DANTAS, (2011)

O desenho do participante B representa a instalação de uma grande empresa, aparentemente um hotel de cinco estrelas, tendo em vista que no lado esquerdo do desenho aparece um grande retângulo, o hotel, vários pequenos quadrados, janelas, e cinco estrelas no topo dele. As estrelas levam a crer o padrão de sofisticação da empresa. Enquanto no centro destaca-se uma empresa uma pessoa, quase do tamanho do prédio, situado na parte central da representação, possuindo um grande chapéu e vassoura, e do lado direito tem-se as casas e casebres, no qual provavelmente pessoa esta se deslocando.

O discente da figura 2 salienta as intencionalidades dos grandes empreendimentos comerciais ao ocupar o solo urbano, desapropriando ou "varrendo" os moradores de suas casas, conforme foi salientado na justifica do mesmo:

"O desenho mostra a imposição das grandes empresas sobre um lugar, onde estas acabam varrendo pessoas que habitavam um determinado lugar, que agora passará por uma grande valorização comercial” (PARTICIPANTE B).

A colocação do participante B enfatiza um dos impactos decorrentes do processo de globalização nos lugares. O que para Santos (2006, p. 194) "a tendência atual é no sentido de uma união vertical dos lugares. Créditos internacionais são postos à disposição dos países e das regiões mais pobres, para permitir que as redes se estabeleçam ao serviço do grande capital", apontando que geralmente as determinações das grandes empresas reorganizam as relações socioeconômicas locais, depreciando as especificidades dos lugares, intensificando o lucro dos agentes hegemônicos, e é neste processo que percebemos claramente a perversidade dos atores. Na figura 3, o professor revela as diferentes concentrações dos equipamentos urbanos percebido em seu cotidiano. 
Figura 3. (PARTICIPANTE C): Desenho do professor de Geografia - Maceió/AL.

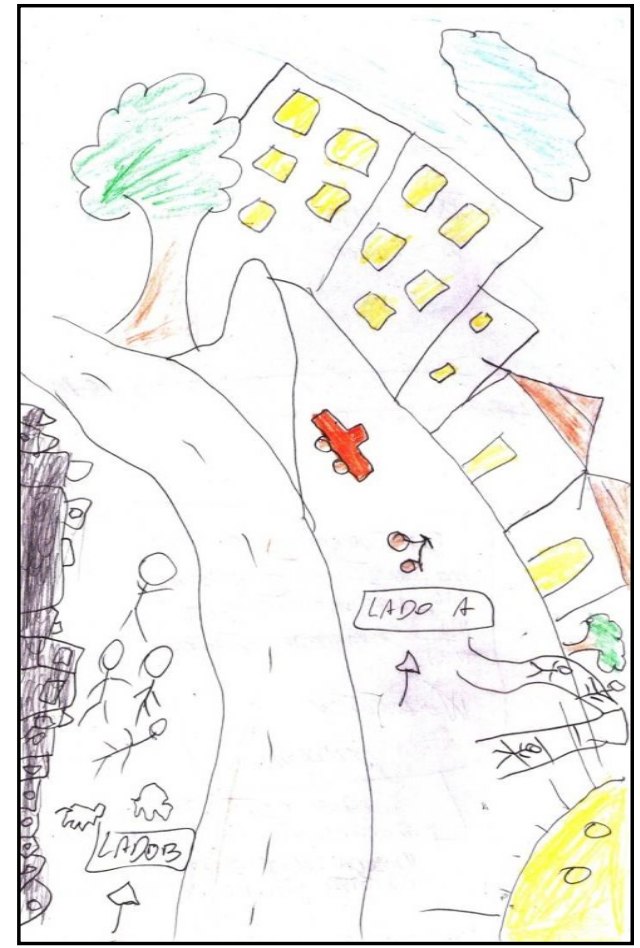

Fonte: DANTAS, (2011)

De acordo com a figura 3 observa-se uma estrada que divide duas dimensões ou como o participante C ressalta adiante, "o Lado A e Lado B": um beneficiado pela melhor distribuição e concentração dos equipamentos no lado A, e o outro, dotado de precariedade, no que se refere, a qualidade de vida dos moradores do lado B.

\footnotetext{
O desenho mostra a relação do cotidiano. A dinâmica social que constrói o lugar. As diversidades presentes no lugar. Desenhei o que vejo no meu cotidiano. Lugares dotados de infra-estrutura qualidade de vida, segurança, etc. (LADO A). Outro lugar marcado pelo descaso e abandono político (LADO B) (PARTICIPANTE C).
}

Na figura 3, especificamente no lado A, tem-se um número maior de casas de alvenaria, prédios, parque de diversão, pessoas, carro, árvores, nuvens e o Sol. A estrada, nessa representação, divide os grupos de moradores, lado B, lado esquerdo da via e lado A, lado direito da via.

Enquanto, na figura 3, o lado B, revela um conjunto de retângulos pintados na cor preta, aparentando ser um conjunto de casas com infra-estrutura bem mais simples, pobre, permitindo vislumbrar que não são de alvenaria, alguns barracos talvez. Há também pessoas e animais, aparentemente.

Tendo em vista o depoimento do participante $\mathrm{C}$ da oficina, podemos deduzir que esta dimensão representada do urbano, compreende uma cidade moderna, dotada de espaços da racionalidade, sobretudo pela técnica e pela tecnologia, (espaços luminosos) e outro, sede da irracionalidade (espaços opacos), além da dinâmica entre as relações de produção (horizontalidades) e circulação (verticalidades), concernente às intencionalidades do sistema de capital.

Na cidade "luminosa", moderna, hoje, a "naturalidade" do objeto técnico cria uma mecânica rotineira, um sistema de gestos sem surpresa. Essa historicização da metafísica crava no organismo urbano áreas constituídas ao sabor da modernidade e que se justapõem, superpõem e contrapõem ao uso da cidade, onde vivem os pobres, nas zonas urbanas 'opacas'. Estas são os espaços do aproximativo e da criatividade, opostos às zonas luminosas, espaços da exatidão. Os espaços inorgânicos é que são 
abertos, e os espaços regulares são fechados, racionalizados e racionalizadores (SANTOS, 2006, p.221).

Nesta perspectiva, a cidade moderna possui um conjunto de objetos técnicos que orientam a maior fluidez de capital, tornando parte dela veloz em relação aos interesses de mercado e o consumo, citando espaços planejados, shoppings com boa iluminação, ruas asfaltadas, com maior acesso aos serviços, ou seja, os espaços luminosos. Mas, na mesma cidade moderna pode haver lugares onde a fluidez do mercado não seja tão intensa, estruturando espaços onde as infra-estrutura não sejam bem preservadas e até nem existam, a saber: as comunidades de países subdesenvolvidos, onde a fome ainda alarma as estatísticas, os quais geralmente podem ser classificados como espaços sede da pobreza e da miséria (espaços opacos).

Os espaços opacos são criativos, mesmo sendo pobres, sabendo que neles é necessário que seus moradores se reinventem, busquem alternativas para garantir sua sobrevivência, frente à competitividade e o consumo voraz. Enquanto, os espaços luminosos são da exatidão, porque já são preestabelecidos pelos agentes que o constitui, tendo o objetivo central de auferir lucro, englobando fatias de mercado para determinadas famílias, empresas, instituições e organismos internacionais, por exemplo.

Os espaços onde o capital tem maior fluidez se justapõem, superpõem e contrapõem porque, no sentido exposto pelo participante $\mathrm{C}$, os objetos funcionais ao lucro ao se instalaram nos lugares, (re)organizando o território, o que leva a "varrer" os pobres para outras localidades. Os espaços do mandar passarão por uma hipervalorização (verticalidades), no sentido imobiliário, porque serão agraciados por infraestruturas e serviços que facilitam o lucro e a vida daqueles que podem pagar bastante por isso, esses lugares vão sendo cada vez mais cobiçados. O que possibilita a reestruturação da divisão territorial do trabalho e deixando de forma clara quem detém o poder e o comando.

Logo, os lugares onde a fluidez do capital é mais intensa, possuem mais força de (re)organização do território, relações de poder nas cidades, chamados de lugares do mandar ou da exatidão (inorgânicos). Ao compararmos com lugares mais pobres, mesmo sendo lócus da criatividade (orgânicos) são desassistidos de estruturas mínimas para a comunidade, tornando-os espaços do obedecer e de uma vida geralmente mais desgastada, isto é, sofrida.

Por conseguinte, na figura 4, o participante D, compreende o conceito de lugar a partir das relações de pertencimento, representando sua casa como o símbolo do aconchego e do bem estar.

Figura 4. (PARTICIPANTE D): Desenho de um professor de Geografia - Maceió/AL.

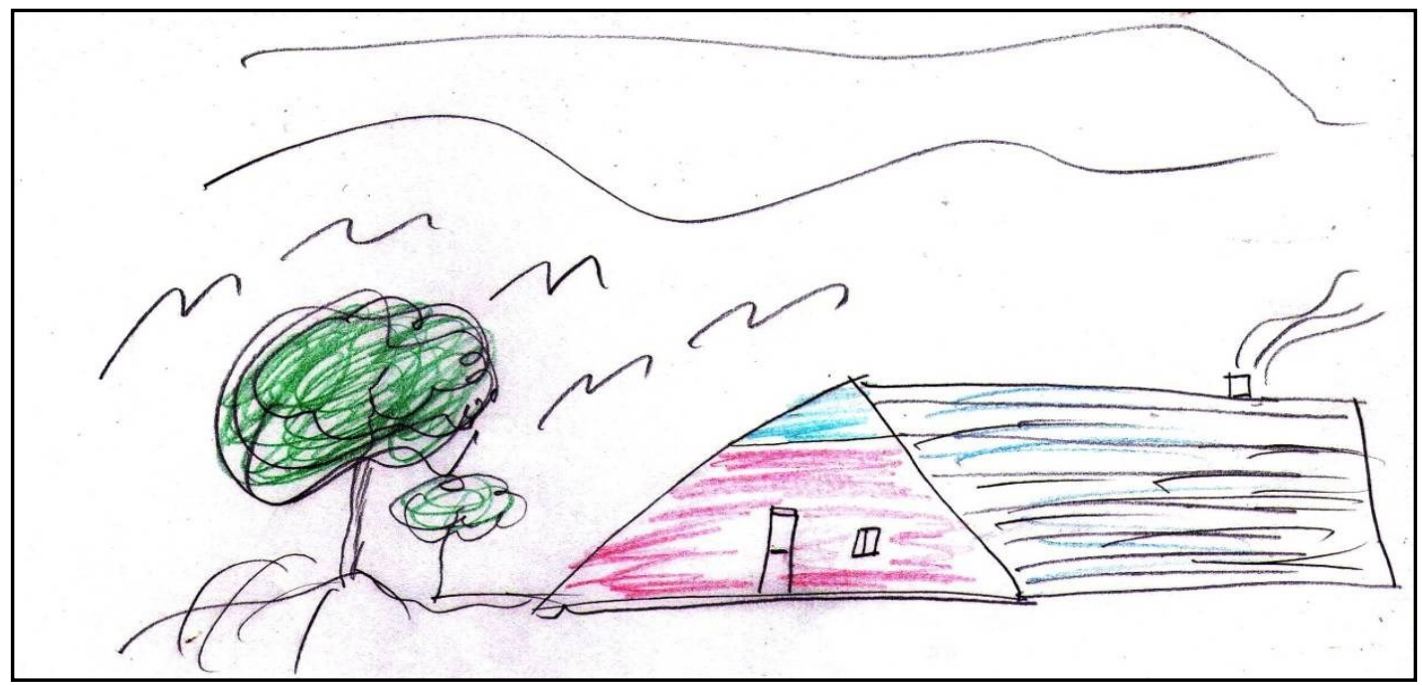

Fonte: DANTAS (2011) 
A figura 4 evidencia uma grande casa na extremidade direita, pintada com cores viva lápis, intensas, e uma chaminé em atividade. Na parte superior, aparecem algumas nuvens e na extremidade esquerda árvores que equilibram o traçado e a idéia de tranquilidade, junto aos pássaros sobrevoando a vegetação.

A justificativa para o referido desenho, o professor de Geografia da escola salienta: "desenhei a casa porque é o símbolo da individualidade, recanto de descanso e aconchego no tumulto do espaço urbano" (Participante D), salientando o conceito de lugar na perspectiva teórica humanística de Tuan (apud LEITE, 1998, p.12), o qual realça o lugar como "um centro de significados construído pela experiência".

Neste sentido, corroboramos com a idéias de Relph (apud LEITE, 1998, p.12) "[...] os objetos e atributos das localizações, mas a tipos de experiência e envolvimento com o mundo, a necessidade de raízes e segurança". Assim, a representações do participante C, levam a entender que lugar também é a morada da quietude em relação a todo ao estressante cotidiano normado da cidade moderna.

As justificativas dos desenhos dos participantes da pesquisa revelam que o desenho se constitui instrumentos de suma importância na perspectiva de entendermos o espaço geográfico, auxiliando a compreensão que estes têm acerca da dinâmica dos lugares e, a importância deste conceito na Geografia Escolar.

Os desenhos revelam uma forte identificação do conceito de lugar à perspectiva humanística, embora outros tenham concentrado o conceito de lugar na perspectiva da leitura crítica dos espaços habitados, enfocando as relações de morada e moradia; de qualidade de vida; das imposições dos empreendimentos comerciais, a exemplo dos lugares marcados pelo descaso e pelo abandono político, percebidos no cotidiano dos diferentes sujeitos.

\section{CONSIDERAÇÕES FINAIS}

A utilização do desenho nas aulas de Geografia auxilia na compreensão dos conceitos, possibilitando os docentes realizarem atividades que possibilitam os discentes revelarem os conhecimentos trazidos em sua cotidianidade. A abordagem do conceito de lugar, quando bem trabalhado, tanto permite aos professores tecer considerações direcionadas a idéia de pertencimento dos alunos com o lugar e com o outro, quanto à dinâmica socioespacial do local e do global ou vice-versa.

Observou-se nos desenhos e justificativas figurativos deste estudo a representação da ação empresarial "varrendo", retirando, comunidades dos seus lugares e levando a acomodar hotéis de cinco estrelas. Outro ponto importante é a questão da escala, considerando a localização de onde os alunos moram em relação ao mundo, representado de forma rotineira, junto às relações de vivência.

Deve-se considerar também que as relações presentes nos espaços de vivência foram representadas como lugares do medo, da insegurança, da pobreza e da violência urbana, situados tanto em alguns bairros periféricos em relação às centralidades econômicas maceioenses, quanto onde moram os mais abastados.

Desse modo, entende-se que ao utilizar o desenho, professores e alunos, podem vislumbrar no dia-a-dia os elementos que fazem parte da escala local, revelando que cada lugar possui seu sistema de ações e de objetos e, que por sua vez trata-se de um conjunto indissociável de sistemas, o qual estrutura o espaço geográfico, objeto de análise da ciência geográfica.

A utilização do desenho na discussão acerca do conceito de lugar na oficina Múltipla Linguagens no Ensino de Geografia possibilitou os participantes da mesma compreender as 
diferentes perspectivas do conceito, reafirmando a sua importância na Geografia Escolar, valorizando a participação dos docentes e discentes no processo de ensino-aprendizagem.

Sendo assim, os resultados deste estudo possibilitou estabelecer um diálogo entre as ideias de alguns autores que se dedicam a Geografia Escolar e os conhecimentos prévios dos sujeitos participantes da pesquisa, evidenciando a relevância da utilização do desenho na compreensão do lugar.

\section{REFERÊNCIAS}

CALLAI, Helena Copetti. Aprendendo a ler o mundo: a geografia nos anos iniciais do ensino fundamental. Campinas, vol. 25, n. 66, p. 227-247, maio/ago. 2005.

CAVALCANTI, Lana de Souza. A educação geográfica e a formação de conceitos: a importância do lugar no ensino de geografia. In: PERREIRA, Marcelo Garrido (org.). La espesura del lugar: reflexiones sobre el mundo educativo. Santiago de Chile: Universidad Academia de Humanismo Cristiano, 2009.

HELLER, Agnes. O cotidiano e a História. $4^{\circ}$ Ed. São Paulo: Paz e terra, 1970.

LEITE, Adriana Figueira. O Lugar: duas Acepções Geográficas. Anuário do Instituto de Geociências -

LUDKE, Menga. ANDRE, Marli E. D. A. de. Pesquisa em Educação: abordagens qualitativas. São Paulo: EPU, 1986.

OLIVEIRA, A. U. de (orgs.). Geografia em perspectiva: ensino e pesquisa, São Paulo: Ática, 2008.

SANTOS, C. O uso dos desenhos no ensino fundamental: imagens e conceitos. In: PONTUSCHKA, N. N; OLIVEIRA, A. U. de (orgs.). Geografia em perspectiva: ensino e pesquisa, São Paulo: Ática, 2008.

SANTOS, C. O uso dos desenhos no ensino fundamental: imagens e conceitos. In: PONTUSCHKA, N.

SANTOS, Milton. A Natureza do Espaço: técnica e tempo, razão e emoção. $4^{\circ}$ ed. São Paulo: Edusp, 2006.

TUAN, Yi-Fu. Topofilia: um estudo da percepção, atitudes e valores do meio ambiente. São Paulo, 